\title{
Modelagem matemática da quantidade de álcool no sangue
}

\author{
Andres David Báez Sanchez Ricardo Nazar Rodrigues* \\ Departamento de Matemática,UTFPR, \\ 80230-901, Curitiba, PR \\ E-mail: adavidbaez@gmail.com, ricnr.10@ @otmail.com,
}

\section{$\underline{\text { RESUMO }}$}

Suponha que haja a necessidade do consumo de determinada quantidade de uma substância, porém esse produto em excesso no organismo causa sintomas colaterais ou até leva a morte. Frente a isso, é natural pensar em como se dá a eliminação em relação à ingestão com o objetivo de quantificar a substância no organismo no tempo $t$ e evitar que ela exceda o limite.

Uma das ferramentas para modelar esse problema Biomatemático, são as equações diferenciais. Elas tem sido usadas para modelar desde problemas de dinâmica populacional até crescimento de tumores entre outros problemas [2], [1]. Muitos destes modelos não tem soluções analíticas sendo necessário o auxílio de Métodos Numéricos, um exemplo é o método de Runge-Kutta, para a obtenção de resultados.

O consumo de álcool é um caso particular do problema mais geral do processamento e controle de substancia perigosas, mas em comparação com outros problemas, há mais estudos e trabalhos nesta área incluindo alguns modelos matemáticos para a variação da concentração de álcool baseados em equações diferenciais. Porém, a ingestão e eliminação simultânea de álcool não tem sido considerada amplamente nestes modelos. Considerar estes fatores na modelagem do problema é relevante, pois levaria a uma melhor compreensão e controle da variação da quantidade de álcool no sangue.

$\mathrm{Na}$ literatura consultada sobre os modelos matemáticos para a dinâmica do álcool no sangue, encontramos dois artigos relevantes que apesar de comentar sobre as três fases do consumo (Absorção, Metabolização e Excreção), não as consideram completamente no modelo. No artigo [4] são consideradas duas equações da seguinte forma:

$$
\begin{aligned}
& \frac{d A}{d t}=-k_{1} A \\
& \frac{d B}{d t}=k_{1} A-k_{2} B
\end{aligned}
$$

Onde $A$ e $B$ são funções da quantidade de álcool no estômago, e no sangue, respectivamente, $k_{1}$ uma constante de absorção do estômago e $k_{2}$ uma constante de eliminação de álcool do sangue. Este modelo considera duas etapas de ingestão (estômago e sangue) mas supõe uma taxa de eliminação em sangue proporcional a quantidade de álcool presente no estomago, o que não é necessariamente realista. Em [3], se considera apenas a segunda etapa da seguinte forma:

$$
\frac{d x_{1}}{d t}=-\frac{\alpha x_{1}}{x_{1}+\beta^{b}}
$$

Onde $x_{1}$ é a função da quantidade de álcool no sangue e as constantes $b, \alpha$ e $\beta$ relativas à taxa de gênero, parâmetro relacionado ao fígado e ao pâncreas, respectivamente. Este artigo é relevante, pois

*Estudante de Graduação 
usando a função racional $-\frac{\alpha x_{1}}{x_{1}+\beta^{b}}$, é possível supor taxa de eliminação limitada por $\alpha$, o que faz mais sentido do que a taxa de eliminação proporcional à quantidade de álcool.

Com base nesses dois artigos vamos considerar o seguinte modelo que além de incluir as duas fases no processo de consumo, e considerar uma taxa de eliminação em sangue limitada usando uma função racional, também levando em conta a função de ingestão, de seguinte forma:

$$
\begin{aligned}
& \frac{d A}{d t}=-k_{0} A+I(t) \\
& \frac{d B}{d t}=k_{1} A-\frac{k_{2} B}{k_{3}+B}
\end{aligned}
$$

Onde $I$ é uma função de ingestão, $A$ e $B$ são funções da quantidade de álcool no estômago e sangue, $k_{0}, k_{1}, k_{2}$ e $k_{3}$ são contantes de eliminação de álcool no estômago, absorção de álcool no sangue, eliminação máxima de álcool no sangue e da dissolução de álcool no sangue,respectivamente. Para a validação visual foi usado o Método Numérico Runge-Kutta de quarta ordem. Implementado em MatLab com o uso de scripts, material complementar. Na Figura 1 são expostas duas politicas de ingestão tendo a constante de eliminação de álcool do estômago como $k_{0}=0.8$ e as constantes de absorção $k_{1}=0.75$, de eliminação $k_{2}=2.5$ e dissolução $k_{3}=5$ de álcool no sangue, com pontos espaçados em 0.001, sendo esses valores definidos arbitrariamente para a visualização do modelo. Na Figura 1 são indicadas em verde a função de ingestão, em azul a função da quantidade de álcool no estômago e em vermelho a quantidade de álcool no sangue.

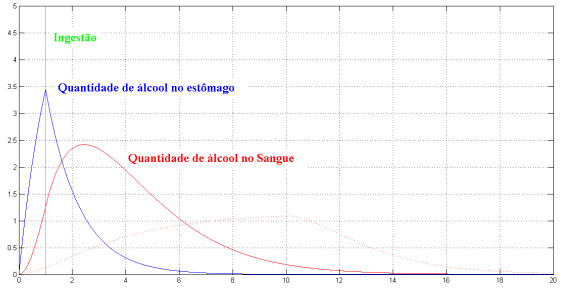

(a) Ingestão 1

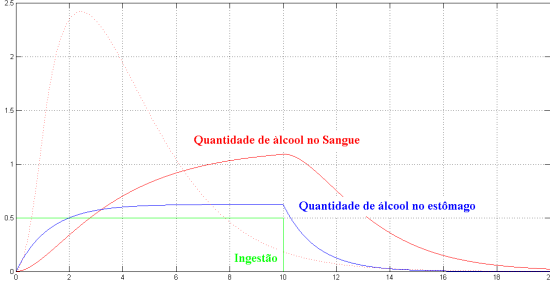

(b) Ingestão 2

Figura 1: Diferentes formas de ingestão.

Esses testes foram realizados tomando como base que a integral da ingestão no intervalo [0,20], que simboliza a quantidade ingerida, é constante e igual a 5 unidades de álcool. Simulado na Figura 1 duas formas constantes de ingestão sendo que em 1a é tida uma ingestão de 5 unidades de álcool durante uma unidade de tempo e em $1 \mathrm{~b}$ uma ingestão de 0.5 unidades de álcool durante 10 unidades de tempo. Note que na figura 1a a quantidade de álcool máxima é maior do que na $1 b$, entretanto se o impacto for calculado acima de 0.1 , não é tão clara qual a melhor forma de consumo .Para quantificar esses valores utilizaremos em trabalhos futuros métodos de integração numérica com o objetivo de solucionar essa questão.

Palavras-chave: Equações Diferenciais, Biomatemática, Modelagem Matemática

\section{Referências}

[1] L. Edelstein-Keshet, "Mathematical Models in Biology", SIAM, Philadelphia, 2005.

[2] D. G. Figueiredo , A. F. Neves, “Equações diferenciais aplicadas”, IMPA, Rio de Janeiro, 2008.

[3] S. J. Kouba , M. B. M. Elgindi , R. W. Langer, Exploring Mathematical Models for Calculating Blood Alcohol Concentration, National Science Foundation, 144-2974/92974.

[4] C. Ludwin, Blood Alcohol Content, Undergraduate Journal of Mathematical Modeling, 3 (2011). 